\title{
Design and Fabrication of Steering Gear Mechanism with Movable Headlights Using Embedded Systems
}

\author{
${ }^{1}$ Kemparaju C.R., ${ }^{2}$ Mohammed Nabeel Ahmed, ${ }^{3}$ B Meghanath, ${ }^{4}$ Mayur Laxman Kesarkar, ${ }^{5}$ Manoj DR \\ ${ }^{1}$ Assistant Professor, Department of Mechanical Engineering, New Horizon College of Engineering, Bangalore, India \\ 2,3,4,5UG Scholar, Department of Mechanical Engineering, New Horizon College of Engineering, Bangalore, India
}

\begin{abstract}
Article Info

Volume 8, Issue 4

Page Number: 180-187

Publication Issue :

July-August-2021

\section{Article History}

Accepted : 20 July 2021

Published: 25 July2021

The main aim of any design must not solely be targeted on customer satisfaction however conjointly customer safety following this the amount of accidents are witness solely because of poor lighting facilities provided in automobiles on curved road static headlights are insufficient since they point tangential it along any point of curve instead of pointing in the vehicles direction so to avoid this problem steering controlled headlamp system has been projected which might hopefully flip out to be a boon to the individual driving through the sinusoidal roads throughout night times. Special safety features are built into cars for years some for the security of car's occupants only, and some for the security of others. One among the alternatives available in design and fabrication of steering controlled headlight system. car safety is important to avoid automobile accidents or to minimise the harmful effect of accidents, especially as concerning human life and health. automobiles are controlled by incorporating steering controlled headlight mechanism. The Ackerman steering mechanism helps the motive force to guide the moving vehicles calls on the road by turning it right or left consistent with his needs thus a combination of the steering system and embedded system link kills the headlights within the direction as per the rotation of the steering wheel. this mechanism has been incorporated in BMW, Audi Q-7 and Benz etc., to make sure a safer drive, but our main aim is to implement the system in all vehicles at lower cost.
\end{abstract}

Keywords - Steering, Car safety, Ackerman, Embedded systems, Headlight system, Curved road Headlights, Safety lights.

\section{INTRODUCTION}

Headlights that adapt to changing conditions are known as adaptive headlights. Their purpose is to give drivers more visibility and time to react to changing conditions. It's a broad phrase that refers to a variety of characteristics, the most prevalent of which being curve-adaptive headlights. The bulbs in these headlights pivot in response to the vehicle's direction of travel-and occasionally speed. Other methods of 
adaptation, such as automated high beams, are referred to as adaptive headlights. In the presence of traffic, these headlights automatically switch between low and high beams. It's also used to indicate adaptive driving beams. These headlights use complex LED arrays to minimize dazzling other drivers. Curveadaptive headlights have bulbs that pivot in the direction of travel of the vehicle. The headlights pivot in that direction as the driver twists the steering wheel left or right, or as sensors detect a bend in the road, to better illuminate what's in the vehicle's path. Curve-adaptive headlights modify the angle of the bulbs in accordance to vehicle speed, allowing them to project closer or further.

Curve-adaptive headlights work with bulbs mounted on motors or servos, which allow the bulbs to pivot. When the driver turns the steering wheel, or when sensors detect a curvature in the road, software or hardware adjust the bulbs in accordance. When the vehicle's direction returns to straight ahead, so do the bulbs. Some curve-adaptive headlights also change the bulbs' angle in relation to speed. As speed changes, the headlights point more up or down, casting light closer or further down the road. To detect other vehicles, automatic high beams use a sensor, usually one that checks for headlights or taillights. When driving on twisting roads at night, during twilight, or in other low-light settings, adaptive headlights come in handy. They can deal with a variety of potentially dangerous circumstances. Cars manufactures which has adaptive headlights like Porsche, Mercedes Benz, Lexus, Ford and BMW.

\subsection{INTRODUCTION TO ARDUINO}

Arduino is an open-source gadget stage based on simple hardware and code. Arduino sheets can recognize inputs such as a light on a sensor, a finger on a catch, or a Twitter message and convert them into outputs such as actuating an engine, turning on an LED, or disseminating something on the internet. We may direct the board by sending a series of commands to the board's microcontroller. To accomplish this, we use the Arduino programming language (in the context of Wiring) and the Arduino Software (IDE) in the context of Processing. Arduino was created at the Ivrea Interaction Design Institute as a simple tool for rapid prototyping intended for students with no prior experience with electronics or programming. Designers and architects use it to create interactive prototypes, while musicians and artists use it to create installations and experiment with new musical instruments. Of course, many of the projects displayed at the Maker Faire are built with it by makers. Arduino is a valuable tool for learning new things.

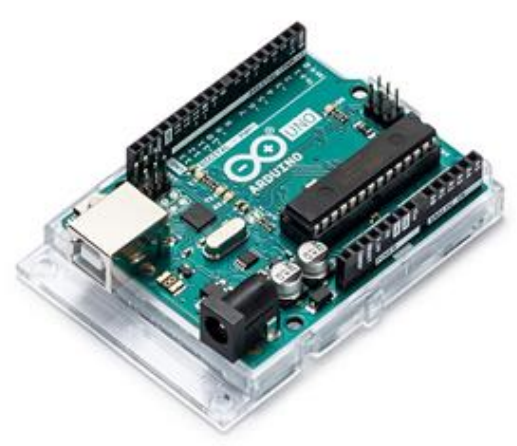

Figure 1.3 : Arduino

\subsection{INTRODUCTION TO SERVOMOTORS}

A Servo engine (or servo) is a revolving actuator that considers exact control of position, speed and speed increase. Servos are found in numerous spots, from toys to home gadgets to vehicles and planes. Servos additionally show up in the background in gadgets we utilize each day. EZ-Robots use servos that deal with the development of joints, container and slant, and nonstop rotational development. The EZ-B v4 conveys an electrical message that mentions to the servo what position to reach and how rapidly to arrive. This sensor tells the circuit board how far the servo yield shaft has turned. The gadgets on the circuit board translate the signs to decide how far the client needs the servo to pivot. It at that point analyzes the ideal situation to the genuine position and chooses which heading to turn the shaft so it gets to the ideal position. 


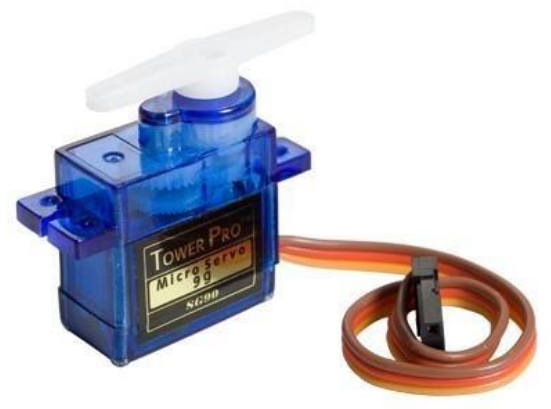

Figure 1.4: Servo Motor

\subsection{INTRODUCTION TO POTENTIOMETER}

A potentiometer is a three-terminal resistor with a sliding or pivoting contact. It is a flexible voltage divider with two static contacts and one moving contact. The moving terminal is a wiper that movements across the obstruction component, for the most part in a bend constrained by a turning knob. The guideline of a potentiometer is that the potential dropped across a fragment of a wire of uniform crosssegment conveying a consistent flow is straightforwardly corresponding to its length. The potentiometer is a basic gadget used to quantify the electrical potentials. One type of potentiometer is a uniform high-opposition wire joined to a protecting help, set apart with a direct estimating scale. Being used, a flexible managed voltage source $\mathrm{E}$, of more prominent extent than the possibility to be estimated, is associated across the wire in order to pass a consistent current through it.

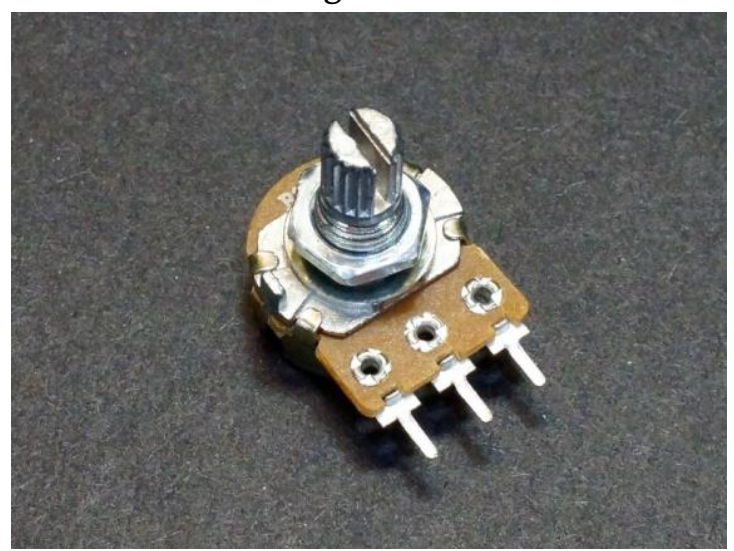

Figure 1.5 : Potentiometer

\section{LITERATURE SURVEY}

A.Saravana Kumar., et., al., [1], [2017]

System is an active safety system, where the head lamp orientation control system rotates the right and left headlights independently and keeps the beam as parallel to the curved road as possible to provide better night time visibility to driver. The highest fatal traffic accident rate occurs on curved roads at nighttime. In most cases, the late recognition of objects in the traffic zone plays a key role. These facts point to the importance of the role of automobile forward- lighting systems. In order to provide enhanced nighttime safety measures, this work aims to design and build a prototype of steerable headlights by adapting a conventional static head lamp with a very close eye on cost and reliability. Components that are easily available in the market are considered and the design has been done to provide the steering mechanism for the headlamps which are actuated along with the steering of the front wheels.

\section{Tushar Wagh., [2], [2020]}

The layout and improvement of an automobile with a movable headlight is for protection to keep away from vehicle accidents. This is finished with the aid of using the use of Carbon Fiber pipes for the chassis and join a headlight to guidance mechanism the use of Ackerman guidance Mechanism. When guidance wheel is rotate that rotary movement is transformed to translatory movement thru Ackerman mechanism. When the front wheel rotates, the front headlight may also rotate on the identical angle. It facilitates for driving force at nighttime driving. In Ackerman System Pitman, Tie rod, guidance arm and rose joints are used. Headlights are linked to the guidance arm in order that headlights can flow consequently to the guidance arm via. Steering wheel. When a car is turning, the internal the front wheel desires to show at a distinctive perspective to the outer because they may be turning on distinctive radii. The Ackermann guidance mechanism is a geometrical association of 
linkages within side the guidance of a car designed to show the internal and outer wheels at the proper angles.

\section{Dr. Ashok Sutagundar., et., al., [3], [2018]}

The aim of this paper is to design and fabricate a simple steering operated headlight system. This device relates to a headlight arrangement operably linked to the steering and front wheel assembly of an automobile, and it should be an efficient substitute for existing traditional methods. The headlights will also focus to the right if we steer the vehicle in the right direction. Similarly, if we turn the car to the left, the headlights would also turn to the left. It is possible to shift the headlights from left to right or vice versa in a continuous manner using a potentiometer. The built headlight system has the advantage of being highly adaptable, as it can be easily modified to fit within the space constraints of a wide range of vehicle designs. Indeed, the latter offers a bending lamp that allows for considerable angular displacement of a headlamp assembly's light beam without causing undue light beam distortion or requiring the entire headlamp assembly to be moved. Furthermore, the device is low-cost, easy-to-assemble, and dependable.

\section{K. Manohar Reddy., et., al., [4], [2015]}

The goal is to design and improve a directional headlight mechanism called a "Steering Controlled Headlight Mechanism." This is accomplished by linking the headlights and steering. The lighting system in today's automobiles is ineffective. As a result, many accidents occur at night, especially in the ghat parts. By adding a Steering Control Headlight Mechanism, accidents can be avoided. This project employs the rack and pinion steering gear mechanism. The rack and pinion mechanism converts rotary motion to translatory motion when the steering wheel is rotated. When the front wheels are steered, the headlights take a similar path and the light is directed in the same direction. The headlights follow the same direction as the front wheels and the light is directed on a more divergent field when the front wheels are steered. The current project involves designing a "Steering Controlled Headlight Mechanism" and fabricating a live model device.

\section{G. Ravi Kumar., et., al., [5], [2016]}

Safety is the primary subject whilst working a motor automobile, apart from functionality. The static headlamp simply provides positive illuminating fields for drivers within side the nighttime and is inadequate to serve for curved roads and intersection, over eighty percentage of all avenue site visitors injuries arise in darkness and horrific weather. The intention is to enhance visibility for the motive force, thereby accomplishing huge growth in avenue protection and riding comfort. Advanced Head-Light controlling system (AHCS) swivel the headlight beams earlier of the automobiles turning. This will place mild into the turning radius, with the end result that the motive force's cornering visibility being dramatically improved. Based in this information, AHCS equipped headlamps can healthy the mild distribution with the automobile's turning perspective in order that upcoming curves and intersections receive most illumination, especially on the driver's gaze point. Headlamps with AHCS remove darkness from the curve of the street whilst the automobile is popping on the curved avenue while headlamps without the AHCS do now no longer Make the whole curved avenue illuminated which blocks the motive force from detecting any pedestrian within side the manner of the automobile.

\section{Manisha V Makwana., et., al., [6], [2017]}

The hardware of a movable headlight system for automobiles is presented in this paper. The headlamp orientation control system rotates the right and left headlights independently and holds the beam as parallel to the curved road as possible to provide better nighttime vision to the driver. In this method, a rack and pinion arrangement provide drive to the optical axes on which the headlights are positioned, 
so that when the tie rod arms are pushed with the steering arm, the wheel and headlights shift in a predetermined manner. The "Automatic Headlamp Steering System" is a system that allows you to steer your headlamps automatically. Curved roads have the highest number of fatal traffic accidents at night.

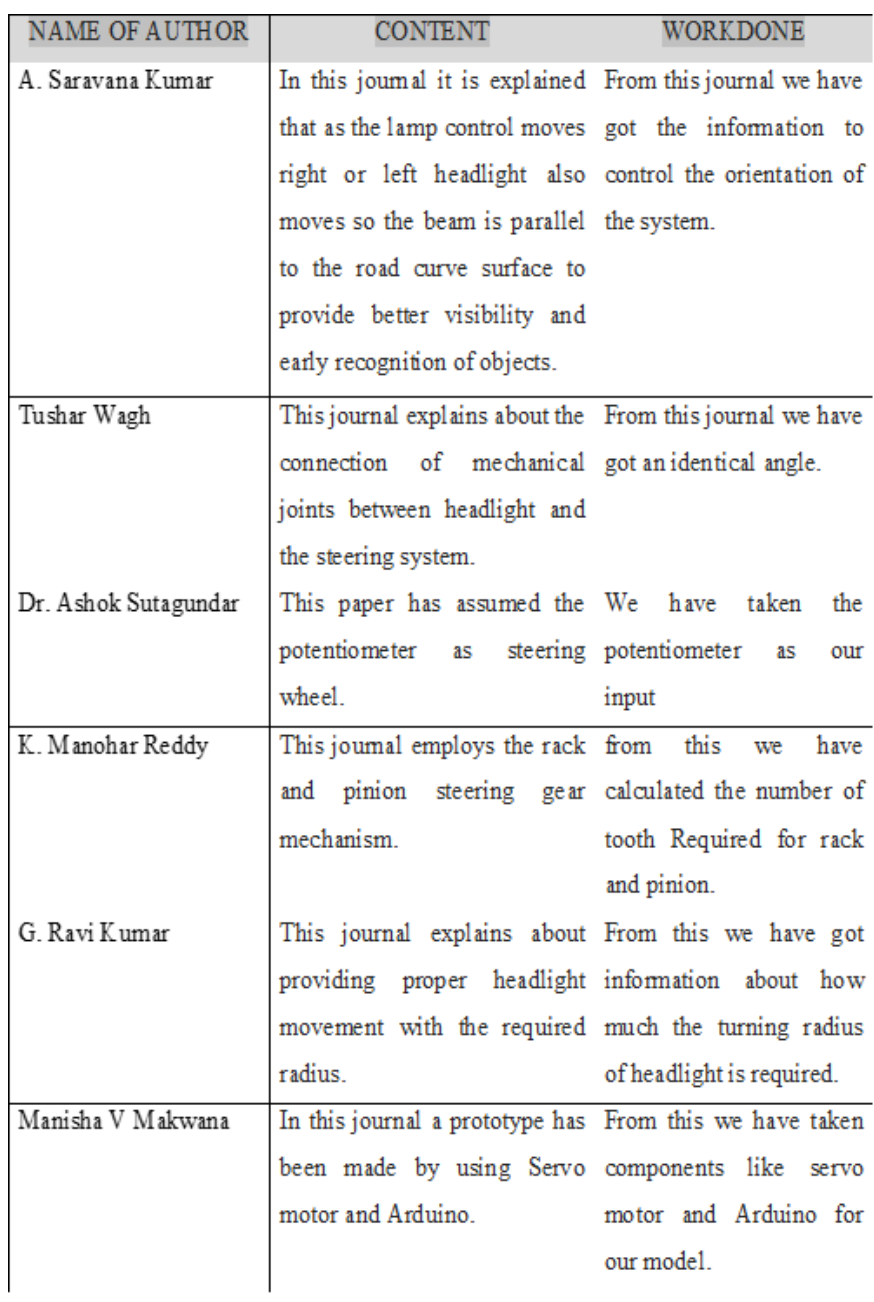

Curved roads have the highest fatal traffic accident rate at night. In the vast majority of situations, late detection of items in the traffic zone is critical. Components that are readily available on the market have been considered, and the design has been completed to provide a steering system for the headlamps that are actuated simultaneously with the steering of the vehicle.

\section{METHODOLOGY}

The project model has been carried out in the following steps:

1. Building a CAD model using SOLIDWORKS as per the dimensions.

2. Creating an embedded system.

3. Creating a program for embedded connections.

4. Simulation

5. Results

\subsection{GEOMETRY}

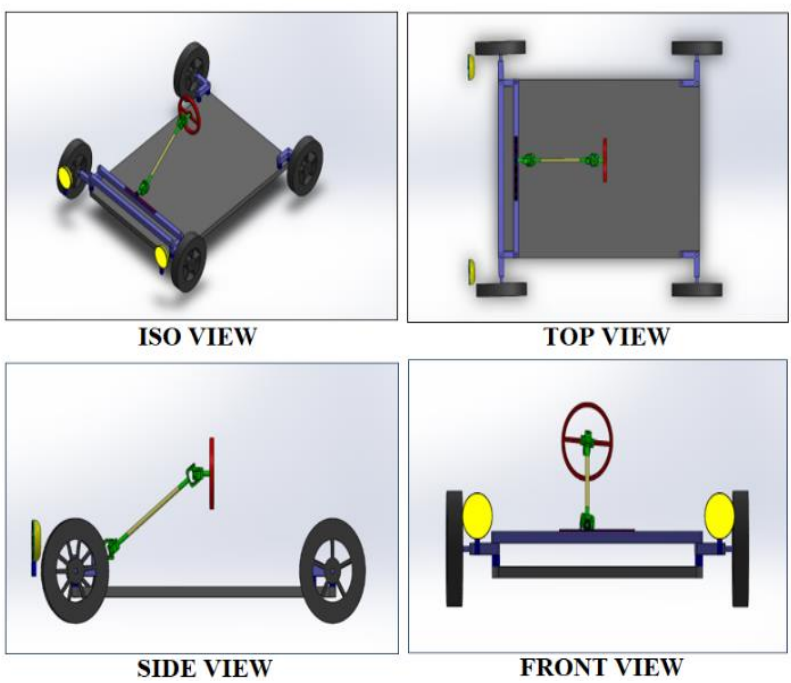

Figure 3.1: Geometry Views

Our model consists of the following components-

1. Steering Gear

2. Arduino

3. Potentiometer

4. Servomotor

5. Headlights

\subsection{WORKING OF ADAPTIVE HEADLIGHTS}

Adaptive driving beams (ADB) are a newer, more technologically advanced type of adaptive headlamp. ADB lights are made up of numerous individuals, very bright LEDs rather than different bulbs for low 
and high beams. The ability to carefully control the brightness of each LED distinguishes ADB headlights.

An electronic control unit monitors and controls adaptive headlamp systems, which are made up of multiple subcomponents (ECU). Among the subcomponents are a steering input sensor that monitors the angle of the steering wheel and small motors attached to each headlight.

When potentiometer rotates which is connected to steering wheel sends signal to Arduino, it converts the analogue signal from potentiometer to digital signal and sends it to the Servomotors, which will change the direction accordingly.

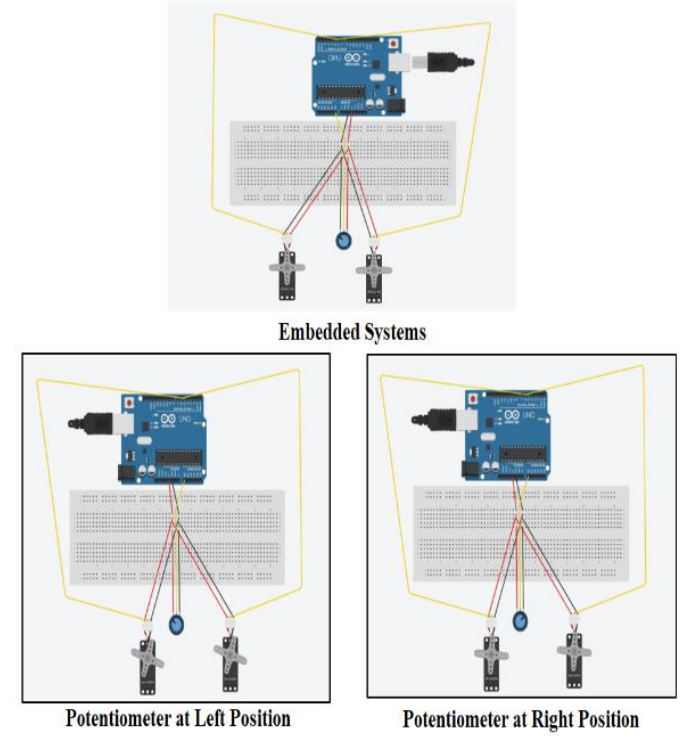

Figure 3.2: Various Positions of Potentiometer

Curve-adaptive headlights use bulbs that are mounted on motors or servos, allowing the bulbs to pivot. When the driver rotates the steering wheel or sensors identify a bend in the road, hardware adjusts the bulbs accordingly. When the vehicle's direction returns to straight ahead, the bulbs do as well.

\subsection{PIN CONNECTIONS}

Arduino A0 - Potentiometer Wiper (Middle Pin) $+5 \mathrm{~V}$ - Servomotor (pin 1), Potentiometer Terminal 2 (Left pin)
GND - Servomotor (pin 2), Potentiometer Terminal 1 (Right Pin)

Arduino 5 and 6 Pin - Servomotor (Signal)

\subsection{CODING FOR EMBEDDED SYSTEMS}

Coding is done for Arduino Uno R3

1. Including the servo motor library

2. Creating 2 servo motors

3. Assigning output of Potentiometer to the analog signal A0 pin in Arduino.

4. Assigning the signal pin of servo motors to pin 5 and 6.

5. Giving an input to both servo motors act symmetrically.

6. Assigned variable to read analog signal from potentiometer and mapping it.

7. Printing the final angle direction from the potentiometer to the servo motor

8. Giving delay of few seconds for servo motor.

\subsection{PROGRAM FOR EMBEDDED SYSTEM}

\#include < Servo.h $>$

Servo myservo1; // create servo 1 object

Servo myservo2; // create servo 2 object

unsigned int servoPin[]=\{5,6\};

int val;

void setup()

\{

Serial.println("Multiple Servo");

myservo1.attach(servoPin[0]); // attaches the servo 1 to the servo object

myservo2.attach(servoPin[1]); // attaches the servo 2 to the servo object

\}

void $\operatorname{loop}()$

\{

val = analogRead(potpin); // reads the value of the potentiometer (value between 0 and 1023)

$\mathrm{val}=\operatorname{map}(\mathrm{val}, 0,1023,0,15) ; / /$ scale it to use it with the servo (value between 0 and 180) 


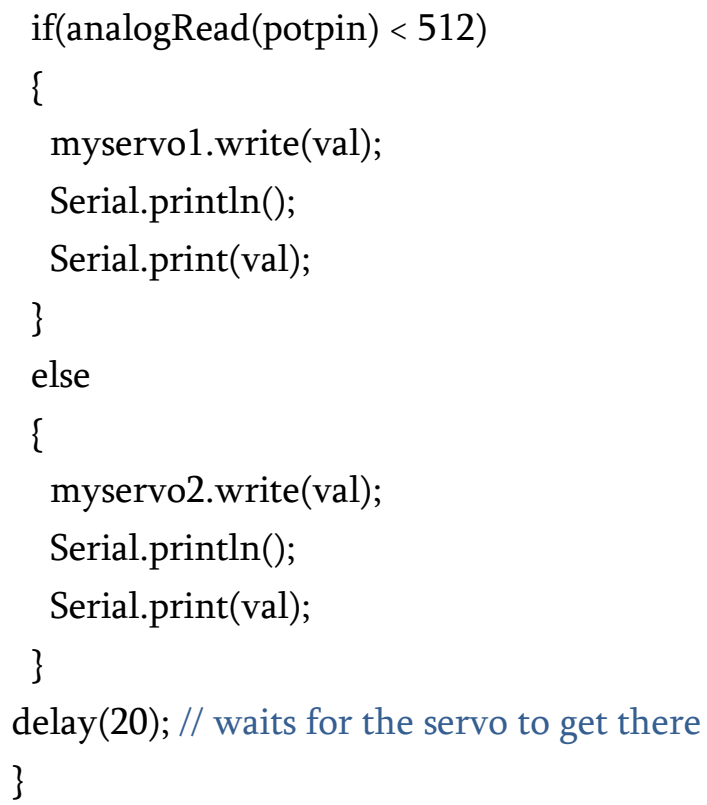

\section{DISCUSSION OF RESULTS}

Curve-adaptive headlights have bulbs that pivot toward the vehicle's direction of travel. As the driver turns the steering wheel left or right, or as sensors detect a curvature in the road, the headlights pivot in that direction to better illuminate what's in the vehicle's path. Curve-adaptive headlights have bulbs that pivot toward the vehicle's direction of travel.

The main reason for accidents in roads having steep turns and curved roads in hilly areas is due to the presence of blind spots. Blind spots are the areas around the vehicle that cannot be directly observed by the driver. These areas cannot be seen directly by looking forward or by looking through either of the side mirrors. Blind spots may occur due to inappropriate positioning of the vehicles' side mirrors, thickness of the A pillar, height and width of the vehicle, etc. Other causes of blind spots are steep curves in roads, lack of visibility due to weather conditions etc. Blind spots can occur due to the condition of the driver as well.
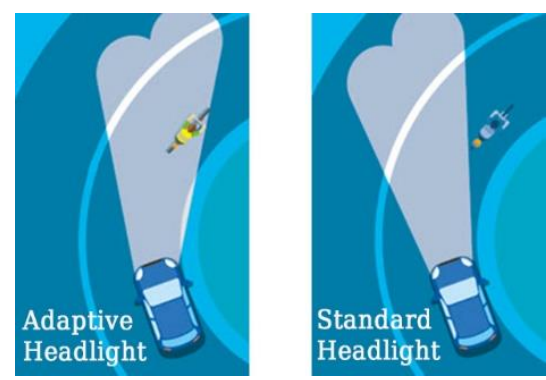

Figure 4 (a): Standard and Adaptive Headlights

when the vehicle is moving in the curved path the vehicle with adaptive headlights have an advantage as shown in figure $4(\mathrm{~b})$ as the driver steers the vehicle the adaptive lights scan the upcoming road by sensors and adapts itself to the road and hence provides a better vision to the driver.

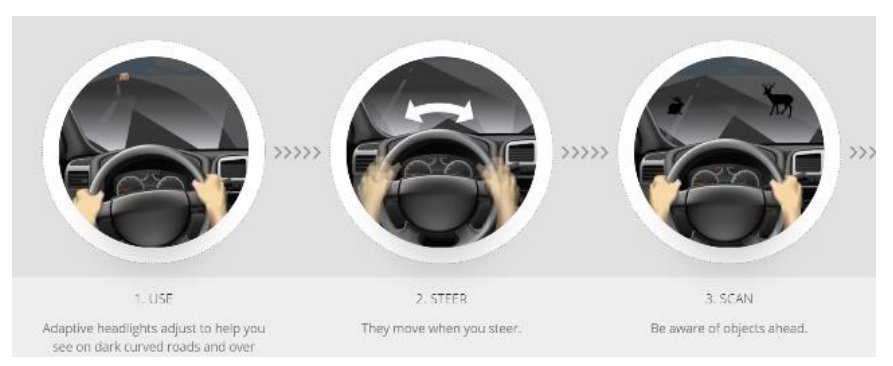

Figure 4 (b): Light Alignment with Steering
When the steering is turned to right only the right servo motor turns to right whereas the left servo remains in straight positions for proper lighting and via-versa.

\section{CONCLUSION}

The project has been a unique experience, successful in utilizing the theoretical knowledge into practical application right from the conception of the idea, through the design and calculations till the assembly processes. There is scope for further improvement in this project, such as the implementation of the various embedded systems in determining angle of deflection of headlights and a system for vertical direction control of headlights depending on various conditions. By using the adaptive headlights, the road accidents can be reduced and safety can be improved this can 
also be implemented at low cost in all vehicles and improve the driver vision at the night time in the curve roads and highways.

\section{ACKNOWLEDGEMENT}

We take this opportunity to express our gratitude to the people who have been instrumental in the successful completion of this project.

We would like to thank our HOD, Dr. Shreedhar Kurse for guiding us in every step. The guidance and support received from all teaching and non-teaching staff of Mechanical Engineering department, New Horizon college of Engineering who contributed to this project. We are grateful for their constant support and help.

We are also grateful to our project guide Prof. Kemparaju C.R., Assistant Professor, Mechanical Engineering Department, New Horizon college of Engineering, for his tremendous support and help. Without his encouragement and guidance this project would not have materialized.

\section{REFERENCES}

[1]. A. Saravana Kumar., et., al., "Design and Fabrication Of Head Light Alignment With Steering System", "International Journal of Pure and Applied Mathematics" Volume 116 No. 19 2017, 547-550, ISSN: 1314-3395.

[2]. Tushar Wagh., "Design And Development Of Electric Vehicle With Movable Headlight", "International Research Journal of Modernization in Engineering Technology and Science" Volume:02/Issue:10/ October -2020, eISSN: 2582-5208.

[3]. Dr. Ashok Sutagundar., et., al., "Automated Headlight System Using Embedded Computing System", "Indian Journal of Scientific and Research" Volume 17 Issue 22018.

[4]. K. Manohar Reddy and U. Mahaboob Basha (2015). Experimental Setup of Steering
Controlled Headlight Mechanism. J. of Advancement in Engineering and Technology. V3I2. DOI: 10.15297/JAET.V3I2.02.

[5]. G Ravi Kumar., et., al., "Advanced Head-Light Controlling System for Automobile", "International Research Journal of Engineering and Technology", Volume: 03 Issue: 10 Oct 2016, e-ISSN: 2395 -0056.

[6]. Manisha V Makwana., et., al., "Design and Manufacture of Movable Headlight System in Automobile", "International Journal of Innovative and Emerging Research in Engineering" Volume 1, Issue 2, 2014, e-ISSN: $2394-3343$.

\section{Cite this article as :}

Kemparaju C.R., Mohammed Nabeel Ahmed, B Meghanath, Mayur Laxman Kesarkar, Manoj DR, "Design and Fabrication of Steering Gear Mechanism with Movable Headlights Using Embedded Systems", International Journal of Scientific Research in Science, Engineering and Technology (IJSRSET), Online ISSN : 2394-4099, Print ISSN : 2395-1990, Volume 8 Issue 4, pp. 180-187, July-August 2021. Available at doi: https://doi.org/10.32628/IJSRSET218433 Journal URL : https://ijsrset.com/IJSRSET218433 